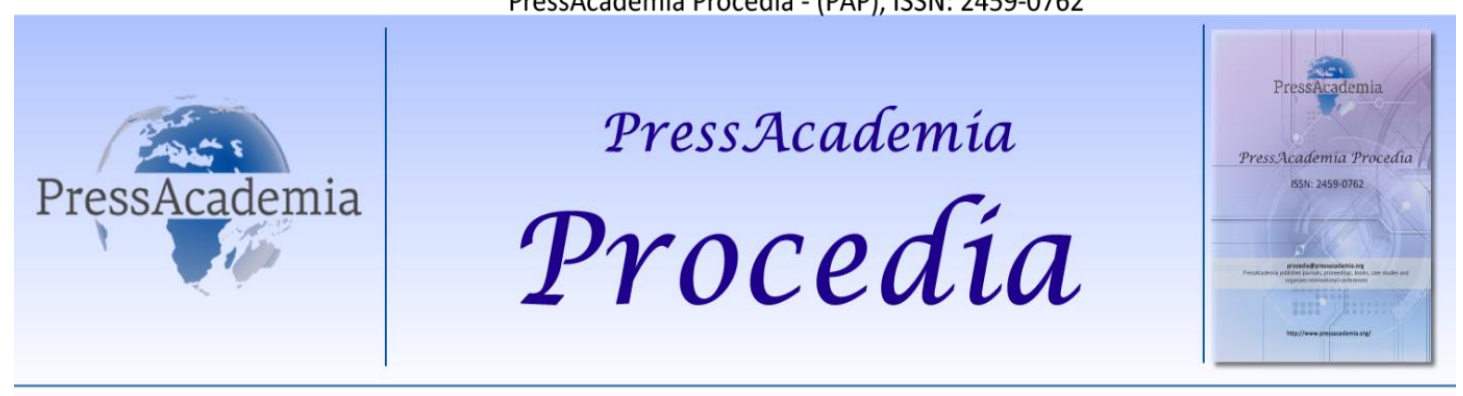

2nd World Conference on Technology, Innovation and Entrepreneurship

May 12-14, 2017, Istanbul, Turkey. Edited by Sefer Şener

\title{
COMPANY INNOVATION SYSTEM: AN EXPLORATION BASED ON EXAMPLES FROM ARÇELIK AND VESTEL
}

\section{DOI: 10.17261/Pressacademia.2017.523 \\ PAP-WCTIE-V.4-2017(15)-p.93-105}

Erik den Hartigh ${ }^{1}$,Pinar Uzun ${ }^{2}$,Ali Auwalu Anwar ${ }^{3}$

${ }^{1}$ Ozyegin University, Istanbul, Turkey., erik.denhartigh@ozyegin.edu.tr

${ }^{2}$ Ozyegin University, Istanbul, Turkey. pinar.uzun@ozu.edu.tr

${ }^{3}$ Ozyegin University, Istanbul, Turkey.ali.anwar@ozu.edu.tr

\section{ABSTRACT}

We conceptualize the company as an innovation system. The systems approach to innovation has received limited attention at the company level. While it is widely accepted for nations, sectors, regions and technologies, and while some company-level building blocks have been proposed, the dominant approach at company level is to regard innovation as a process. A company innovation system consists of interacting components with the purpose to produce innovation. Those components can be actors, resources or institutional characteristics. The components can be configured and reconfigured for different purposes. An innovation process is therefore one of the many possible configurations within a system. A systems approach emphasizes part-whole interactions and evolutionary dynamics. We explore the concept of company innovation system using case examples of two Turkish electronics manufacturers: Arçelik, with its Telve Turkish coffee machine, and Vestel with its 3D Smart TV. We find that using the company innovation system approach, we can map innovation systems at the company level, we can indicate the relationships between the components of the system and we can identify system characteristics such as open versus closed, archetypical configurations, where new combinations come from, coordination mechanisms and exploration versus exploitation. As such, we can address questions about the company's innovation management that are difficult to address by using a process approach. We conclude that the company innovation system approach provides additional and complementary insights to the existing company-level innovation approaches.
\end{abstract}

Keywords: Company innovation system, Arçelik, Vestel.

\section{INTRODUCTION}

We conceptualize the company as an innovation system. The systems approach to innovation management has received limited attention at the company level. Innovation systems approaches have been proposed for and successfully applied to countries as National Innovation Systems (Lundvall, 1992), to regions as Regional Innovation Systems (Cooke et al., 1997), to sectors as Sectoral Innovation Systems (Malerba, 2002), and to technologies as Technological Innovation Systems (Carlssson \& Stankiewicz, 1991). In each of those fields, the innovation systems approach is widely accepted.

Van de Ven (1986), Teece (1996), Granstrand (1998, 2000); Lakhal et al. (1999), Coriat \& Weinstein, 2002 and Chen et al., 2015 proposed various building blocks for conceptualizing the company as a system of innovation. Still, at the company level, the dominant textbook approach is to regard innovation as a process (see, e.g, Trott, 2011; Tidd \& Bessant, 2013). The introduction of the Stage-Gate system by Cooper (1985) greatly contributed to the acceptance of the process view. Initially, many companies regarded innovation processes as purely sequential steps, but later it was recognized that it is more effective to use cross-functional mechanisms, parallel processing and non-linearity within the innovation process (see, e.g., Cooper 1990). Cooper (2008) debunks many of the myths that the Stage-Gate system would be rigid and sequential, while still recognizing that many companies have implemented it as such. 
With the advent of open innovation, companies and researchers have increasingly adopted a network approach in addition to the process approach (Chesbrough, 2003). Authors developing concepts of business ecosystems and platforms (Moore, 1993; lansiti \& Levien, 2004; Gawer \& Cusumano 2014) have extended this network approach into a systems approach, in which the company is one of the actors within a technological system or platform.

With a network approach researchers emphasize the structure of a system, e.g., the numbers of nodes and links and the connectedness between the nodes. Links are usually represented as ' 0 ' (no link) or ' 1 ' (link). With a systems approach researchers look beyond the structure, emphasizing the exchange relationships between the nodes and the emergent properties at the system level. A systems approach to innovation emphasizes interaction, learning and knowledge creation. It allows inclusion of a wide array of institutional attributes that may be important in explaining innovation, such as innovative culture, top-down or self-organized coordination, or an open versus closed mindset.

\section{THEORY}

In this section we first discuss building blocks for conceptualizing the company as an innovation system that have been put forward by various authors. Then we discuss some analytical and methodological aspects, drawing heavily on Carlsson et al. (2002). We then proceed to sketching the outline of the company innovation system concept.

\subsection{Building Blocks for a Company Innovation System Concept}

Granstrand (2000) coined the concept of corporate innovation system and defined it as "...the set of actors, activities, resources and institutions and the causal interrelations that are in some sense important for the innovative performance of a corporation." (p.14), a definition that is in line with the concepts of national, regional, sectoral and technological innovation systems. He studied such systems in different county contexts, on an aggregate country level, identifying a number of important characteristics and developments, such as the growing importance of external technology acquisition and the increasing diversification of companies' technology base. He also investigated implications for growth and performance. Grandstrand's (2000) is the most comprehensive study on this topic to date, but results are presented at an aggregate level, and could be more informative for developing the concept at the company level.

Van de Ven (1986) provided a foundation for company innovation systems in his discussion on "problems in the management of innovation". One of the main problems in innovation, he argues, is the management of partwhole relationships. A tempting and much-used approach for achieving maximum productivity is to segment innovation into a sequence of stages and to divide the labor among specialist departments, like R\&D, production or marketing. Such approaches have turned out to be inadequate for complex, interdependent activities like innovation because the efficiency of the micro-structures too often leads to macro nonsense (Van de Ven, 1986). An alternative, he proposes, would be to use simultaneous coupling of business functions, based on the hologram/brains metaphor of Morgan (1986). This requires radically different design principles for the organization of innovation, specifically: 1) allowing the collection of actors responsible for innovation to selforganize, 2) creating redundant functions, rather than narrow specialisms, 3) assuring requisite variety (Ashby, 1962), meaning that the complexity of the internal system should be large enough to deal with a the complexity of the environment, and 4) using temporal linkage, meaning that actors can configure into groups, change configurations, eliminate configurations and reconfigure into different groups, based on the demands of their innovation task. For these principles to work, Van de Ven (1986) continues, the system needs the governance, institutional characteristics and infrastructure that enable it to learn. This requires network-building inside and outside the organization.

Teece (1996) identified different archetypes of such governance based on the institutional characteristics of external linkages, hierarchical decision making, change culture, scope, and vertical integration. As archetypes Teece (1996) identified the multiproduct integrated hierarchy, the high flex Silicon Valley type, the virtual corporation and the conglomerate. Each archetype facilitates specific types of innovation and the creation of or access to specific types of capabilities.

Granstrand (1998, p.475), in his conceptualization of the technology-based firm, views a firm as "... a legally defined, dynamic human system, consisting of a set of heterogenous resources in an institutional setting ...". He identifies resources as the most important components of the system and he provides a detailed discussion of these resources, namely physical capital, financial capital, intellectual capital, relational capital and human embodied capital. 
Lakhal et al. (1999) introduce the concept of a networked company. It consists of four basic components: 1) elementary resources, not unlike Granstrand's (1998) resources, 2) elementary methods, by which they mean procedures or technologies to accomplish a task, 3) elementary activities, by which they mean a grouping of resources and an associated method, that converts inputs into outputs, and 4) product, which are the outputs of these elementary activities. The company, then, is a large collection of resources and methods, that are grouped in activities. Activities can be chained together, with intermediate inputs and intermediate outputs, into productmarket chains that convert supply market inputs into consumer market outputs. Lakhal et al.'s (1999) concept is not necessarily innovation-related. Although named 'networked company', the concept has many systems characteristics.

Coriat and Weinstein (2002) set out to bring together the organizational and institutional dimensions of innovation systems. The organizational dimension is mostly concerned with the organizational structure for innovation activities, the modes of coordination between the activities and the governance. They identify two main questions. The first is "How can one understand both the diversity of organizational patterns and the existence of dominant modes of organization?" (p.276). This question is related to Van de Ven's (1986) design principle of requisite variety - different environments require different levels of system complexity - and to the principle of temporal linkage - some organization modes are successful across environments and over time, and will tend to more permanent linking, exploiting existing resources and capabilities. Coriat and Weinstein's (2002) second question is "How can organizational patterns evolve to give birth to new principles and organizational systems?" (p.277). This question is related to Van de Ven's (1986) design principle of self-organization - given a new and unknown task, the system will reconfigure to try and solve the task - and also to the principle of temporal linkage - unsuccessful modes or modes that are not continually required will dissolve and be replaced by other modes, exploring new routines and building capabilities. Coriat and Weinstein (2002) warn against treating the company as a closed system, explaining that the company - and, consequently, its dynamics - is a part of the wider institutional environment. They interpret this institutional environment mainly as the national or sectoral systems of innovation that the company is a part of.

Finally, Chen et al. (2015) mention the concept of a 'firm innovation system'. Not unlike Teece (1996) they identify a number of archetypes of innovation systems, using Rothwell's (1994) five innovation generations as a starting point. The use of Rothwell's (1994) generations also implies a generic evolution in how companies structure and lead their innovation systems over time. Specifically, Chen et al. (2015) identify: 1) the internal R\&D-oriented innovation system, with a dominant technology-push role of internal R\&D, 2) the internal and external collaborative innovation system, with interconnected R\&D, marketing and manufacturing functions, 3) the highly strategy-oriented innovation system, led from the business strategy by the CEO or Chief Innovation Officer, and 4) the ecological innovation system, which departs from the company level and sees the company as an actor in a business ecosystem.

\subsection{Aspects of Innovation System Concepts}

Carlsson et al (2002), in their paper on analytical and methodological issues for innovation systems, indicate that systems consist of components, the relationships among them, and their characteristics or attributes. Components are actors, artifacts (cf. the resources mentioned by Granstrand, 1998), and institutions (such as laws, traditions and norms). The relationships between the components are essential for the formation of a system: the parts influence each other, the parts influence the whole and the whole influences the parts. Such relationships, Carlsson et al. (2002) argue, can be market-based on non market-based. The feedback loops in the relationships provide the dynamics of the system. Attributes are properties of components and relationships, such as capabilities for selecting markets, technologies and organization modes, organizational capabilities for coordinating and integrating activities, functional capabilities for executing tasks efficiently, and adaptive capabilities that allow the system to learn from success and failure. Next to this, the system has dynamic properties, such as robustness, flexibility, the ability to generate change and the ability to respond to changes. Such changes, they argue can be endogenously or exogenously induced. Carlsson et al. (2002) define three major methodological issues to resolve for conceptualizing a system: 1) what is the level of analysis?, 2) what is the definition of the system boundary?, and 3) what constitutes system performance, a question that is related with the system purpose with the defined system outputs?

\subsection{Company Innovation System}

For the company innovation system concept, we follow the 'template' for innovation systems as put forward by Carlsson et al. (2002). Drawing together the building blocks discussed above, we conceptualize of the company as a system of interacting components that has the purpose to produce innovation. These components can be actors, such as individuals, groups, departments or business units, they can be resources, such as financial 
capital, intellectual capital or human capital (embodied in the actors and/or their relationships), or they can be institutional characteristics, such as innovative culture, closed versus open or rigid versus adaptive.

The components of the innovation system can be configured, by top-down coordination or by self-organization, into configurations that address specific tasks, e.g., one configuration focuses on coming up with new ideas, another configuration focuses on developing and launching a new product (see figure 1). We further argue that these configurations can range from temporary to permanent. Successful configurations around recurring tasks are expected to be more permanent, reflecting the company's exploitation of existing resources, activities and capabilities. Configurations meant to discover new combinations or unsuccessful configurations will be more temporary and reflect a company's exploration activities and the building of new resources and capabilities. Looked at in this way, an innovation process becomes a specific configuration mode of components of the innovation system. The company innovation system approach therefore does not replace or compete with the process approach, but generalizes it.

Figure 1: Company Innovation System

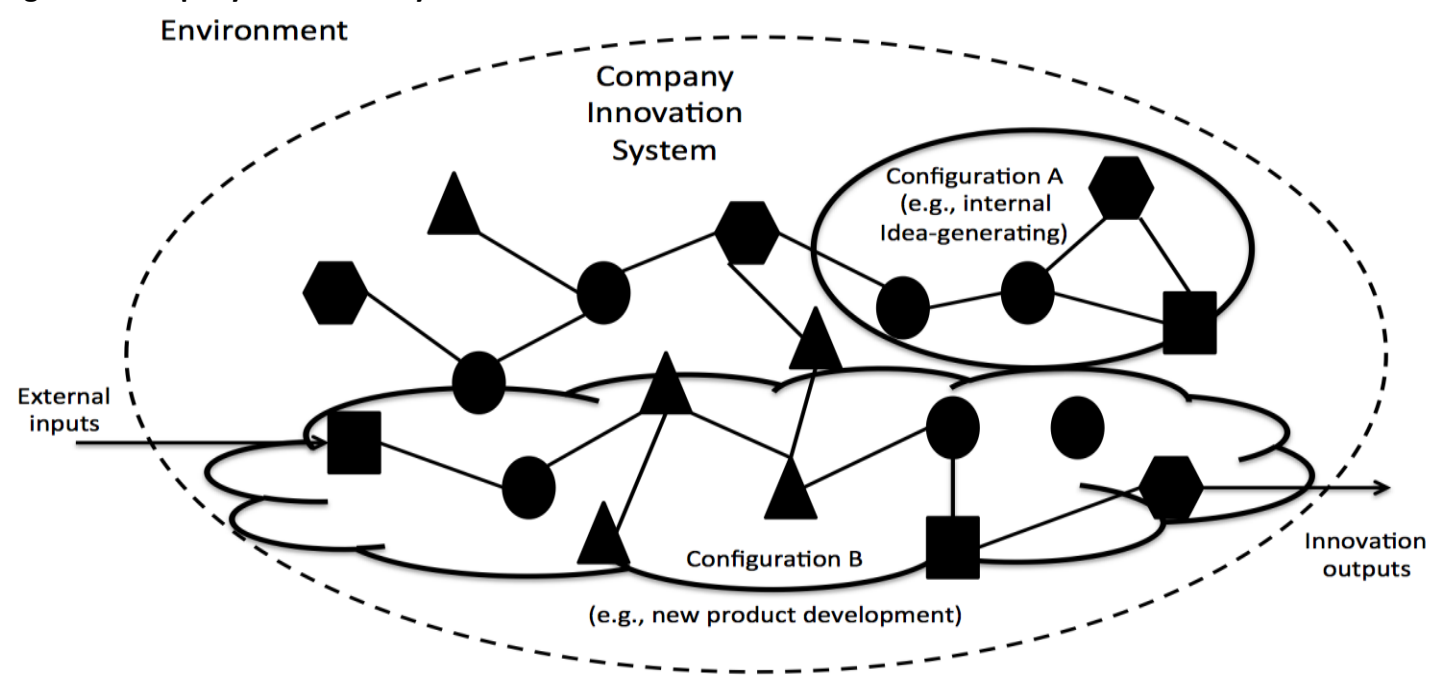

We emphasize that not all the system's actors and resources need to be involved in every configuration. Indeed, different configurations can exist simultaneously, partly overlapping and using the same actors and resources, while perhaps leaving other actors and resources unused. The use of actors and resources for different tasks, or the (temporal) lack of use of some actors and resources align with Van de Ven's (1986) design principle of 'redundancy of functions': the capacity of the system is larger that what it actually needs for any specific configuration, but prepares it for wider needs.

Like any system, a company innovation system has an environment, i.e., that which is outside the company, and it interacts with this environment, exchanging inputs and outputs with it. Like the system's own resources, such inputs and outputs can be physical, financial, intellectual, relational and human. External innovation systems such as platforms, business ecosystems, technology systems, regional, sectoral and national innovation systems are important parts of that environment.

That leaves us to address the three methodological issues as put forward by Carlsson et al. (2002). First, the level of analysis for a company innovation system this is fairly clear, as it will be either the corporate or the business unit level. We need to be careful not to mix the levels, although they can be analyzed together as long as it is clear on which level we are. Second, we define the system boundary for the moment very straightforward as the legal boundary of the company. A possible alternative would be to use a stakeholder-based definition that would include, for example, subcontractors working within the company or temporary laborers. Furthermore, as argued by Coriat \& Weinstein (2002) and as shown in the concepts of Chen et al. (2015) the company innovation system may be strongly intertwined with wider ecosystems or regional, sectoral or national systems of innovation, and it may in practice not be so easy to define what is 'inside' and what is 'outside'. The dynamics of the system mean that the company boundary may evolve over time. Next to organic evolution of the company, this may be the result of mergers or acquisitions, or of all kinds of spin-out and source-in modes that result from open innovation. Third, we define the purpose of a company innovation system in a broad sense. Its outputs and performance can include different types of innovation (product, technological, business model, organizational) with different rates of innovativeness (e.g., incremental, radical), different rates of success or failure and different rates of impact on the company, the market or the world. 


\section{METHOD}

We explore the concept of company innovation system by using two case examples. The first one is Arçelik, a Turkish consumer electronics manufacturer, with its innovation of the Telve Turkish coffee machine. The second one is Vestel, also a Turkish consumer electronics manufacturer, with its innovation of the 3D Smart TV. To construct the case examples, we developed a detailed case protocol, part of which we show here:

1- Basics of the innovation

2- The internal innovation system of the company

a- Is innovation represented at the executive level? Does the company have a "chief innovation officer" or "chief technology officer"?

b- $\quad$ What are the main components (actors, departments, units, incubators, central or de-central $R \& D$ departments or laboratories, etc.) involved in innovation?

c- How are these components related to create innovation?

d- $\quad$ A picture of the components of the innovation system and how they are related

3- Innovation generations ('archetypes' of configuration, see Rothwell, 1994; Ortt and Van der Duin, 2008)
a. Technology push model
b. Market pull model
c. Interactive model
d. Open innovation model

4- Impact and performance of the innovation

The second author analyzed the Arçelik case. The third author analyzed the Vestel case. The first author checked both cases for completeness in analyzing the questions from the case protocol, for internal consistency and for mutual consistency. For constructing the case examples we used only publicly accessible data, like the company website and its annual reports, press releases, media coverage, academic articles and earlier case studies. The detailed case protocol and the complete case example documents can be obtained from the authors upon request.

\section{RESULTS}

We describe the case examples of Arçelik and Vestel below. Subsequently we discuss them by making a crosscase comparison and deriving implications for our company innovation concept.

\subsection{Arçelik and the Telve}

Arçelik is a Turkish household appliances manufacturing company. It started operations in 1955 and today is the market leader in the appliances sector in Turkey. Moreover, it is one of the top five white good manufacturing companies in Europe. With over 2000 patent applications, Arçelik currently accounts for $10 \%$ of all the patent applications in Turkey (Arçelik Annual Report 2016). Arçelik received "R\&D Leadership" and "Leadership in Technology Development" awards during the Third Turkey Innovation Week. Also, it was chosen as Turkey's most innovative company in 2014 (Arçelik Annual Report 2014).

Arçelik introduced the world's first Turkish Coffee Machine, the Telve, in December 2004 (Arçelik Annual Report 2004). It delivers a traditional foamy Turkish coffee quickly without making users have to wait for it to brew. Making Turkish coffee has become much easier since Telve was introduced: all that needs to be done is put water into the machine, put Turkish coffee and sugar in the cup and push the button.

\section{Arçelik's company innovation system}

Arçelik started systematic R\&D activities in 1991 with the foundation of its first R\&D center (Arcelik website), which is relatively late compared to its international competitors. With its innovation practices, Arçelik sets a benchmark for companies in Turkey. Main components of Arçelik's strategy are design, quality, technology and innovation (Arçelik Annual Report 2016). Arçelik differentiates between technology management and innovation management. When the Telve was first introduced in 2004, Arçelik had an executive responsible for technology. Currently Arçelik has both an executive responsible for technology and a director responsible for innovation. 
Arçelik has R\&D departments in each plant in addition to an R\&D department in its headquarters. The task of the headquarters R\&D is to manage processes, rather than do the detailed research or development. Innovation activities within the business are managed by project groups consisting of employees that work in those business units. These project groups are managed by the innovation directorate which directly reports to the general manager. Arçelik is in the process opening a new prototyping centre, Atölye Labs, to create an attraction point and to enable an open innovation system that engages engineers, makers and technicians at the central R\&D Campus of Arçelik.

The Telve innovation appeared from a combination of open innovation and an interactive model of innovation, because Arçelik combined external and internal and technological and market-based ideas to develop the innovation. Arçelik carries on long-term strategic collaborations with universities and research centers that are specialized in R\&D. Arçelik supports laboratories located in Istanbul Technical University and collaborates with more than 20 universities abroad. It is involved in various innovation collaboration and platforms both in Turkey and abroad. Arçelik makes use of open innovation platforms and also hunts for early stage technology (Arçelik Website). Figure 2 shows Arçelik's company innovation system.

Figure 2: Arçelik's Company Innovation System

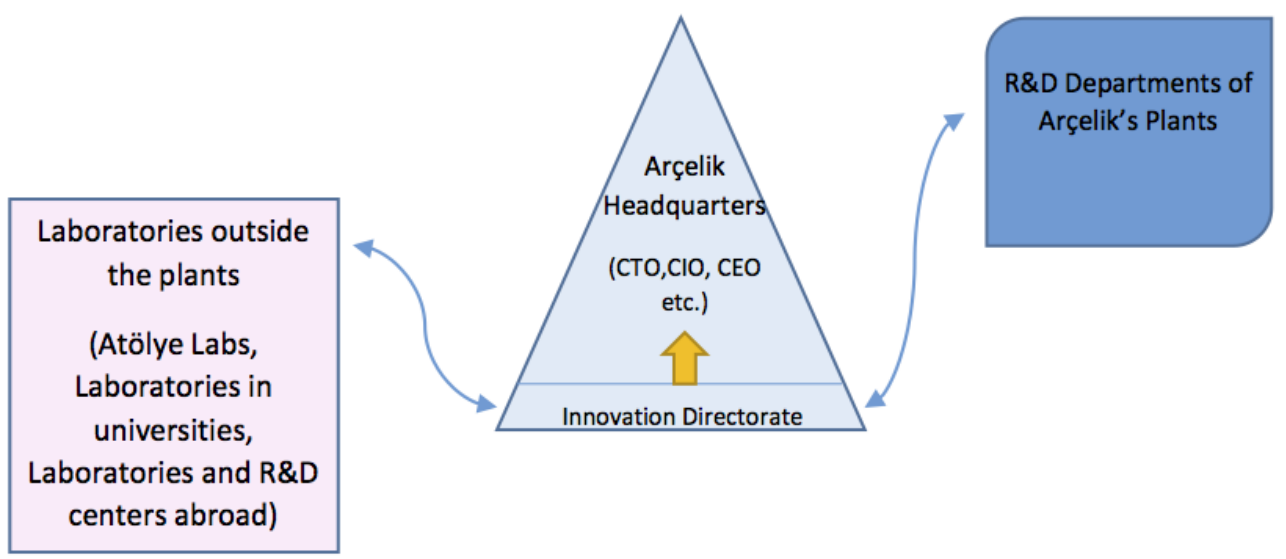

\section{The Telve and its impact}

Telve is a radical and architectural product innovation. It is unlike any other coffee machine and it is based on a new set of engineering principles. In 2004, it was new to the market and new to the world. When Telve was introduced, it attracted great attention. Telve was patented with three technologies, consisting of eight patent applications in total. Cook-Sense technology allows the machine to determine the time that is needed for brewing, considering the amount of coffee and sugar that has been put in. AntiSpill technology allows users to be alerted and the machine to switch off when the Turkish coffee is ready. Spin-Jet technology transfers the water from the container to the pot and then it mixes the ingredients homogeneously before the brewing starts (Başarır, 2005)

Telve received the IF Design Award at CeBIT in 2005, one of the world's most prestigious awards (Turkish Coffee World, 2016). Telve has become a commercial success for Arcelik, creating a new market and contributing to the company's sales, profits and brand image. Technologically, Telve has become a dominant design that is now adopted by new entrants in the market. Its social impact has been to change the Turkish Coffee making habits of consumers. The innovation has a good fit with Arçelik's business model and innovation model. Arçelik did not change itself with this innovation, but reinforced its existing capabilities and performance.

\subsection{Vestel and the 3D Smart TV}

Vestel is a Turkish home and professional appliances manufacturing corporation, consisting of 18 companies specialized in electronics, major appliances and information technology. It is one of the world's largest TV manufacturers, producing its own brands as well as manufacturing OEM products. Vestel and its subsidiary brands have a significant share in the European markets of consumer electronics and home appliances, in particular TV sets, where it accounts for about a quarter of the European market.

The Vestel 3D Smart TV, introduced in 2012, is a television that offers 3D viewing, enhancing viewers' experience along with a traditional 2D option. It offers dual view capability where viewers can watch two different programs 
in full-screen on the same TV, looking at the same screen simultaneously. This also allows for dual play where customers can play video games with companions, both enjoying a full screen instead of the traditional split screen.

\section{Vestel's company innovation system}

Innovation is not officially represented at the executive level of Vestel. The company has no chief innovation officer or chief technology position. Unofficially however, board member Emre Zorlu may be identified as a representative of innovation at the executive level of the company: "Emre Zorlu is currently also the ViceChairman of Vestel Ventures, the venture capital arm of Vestel, focusing on early stage technology, innovation and IP investment, commercialization, and advisory" (Vestel Ventures, 2015).

Vestel has four R\&D centers in its main location, Vestel City in Manisa. Three of these are Electronics R\&D centers and one is a White Goods R\&D center. Other Vestel R\&D centers include VESTEK at the Istanbul Technical University Teknopark, where development activities are carried out for IPTV, 3D algorithm and server software used in TV interaction, Cabot UK, which develops middleware software for digital broadcasts, Vestel Elektronik Shenzhen R\&D Office, which operates mainly in the area of component certification and IA design and development company in Silicon Valley (Vestel Annual Report 2015).

Vestel R\&D centers closely collaborate with a number of national and international institutions and agencies, especially universities. Vestel cooperates with Ege University Science and Technology Centre (EBILTEM) in Izmir: "EBILTEM is an interface organization of Ege University, and an internationally recognized university-industry collaboration institution housing a wide range of offices and units providing information, technology, IPR and innovation management support to industry" (Senturk, 2011).

The company seems to work on both ends of the exploration - exploitation scale. Its initiatives to expand its current product-line and its contract manufcturing for OEM's are fairly safe, geared toward efficiency, and the company can continue to perform like it always has. On the other side of the spectrum, the company commits to developing disruptive technologies that require new technological capabilities. The 3D Smart TV is an example of this last approach. The 3D Smart TV appeared from a combination of open innovation and a technology-driven model. The company seems to gather research results and concept ideas from, e.g., EBILTEM and from its 'satellite' R\&D centers abroad. Utimately, final tests and innovation production are done in Vestel's R\&D centers in Manisa. Figure 3 shows Vestel's company innovation system

Figure 3: Vestel's Company Innovation System
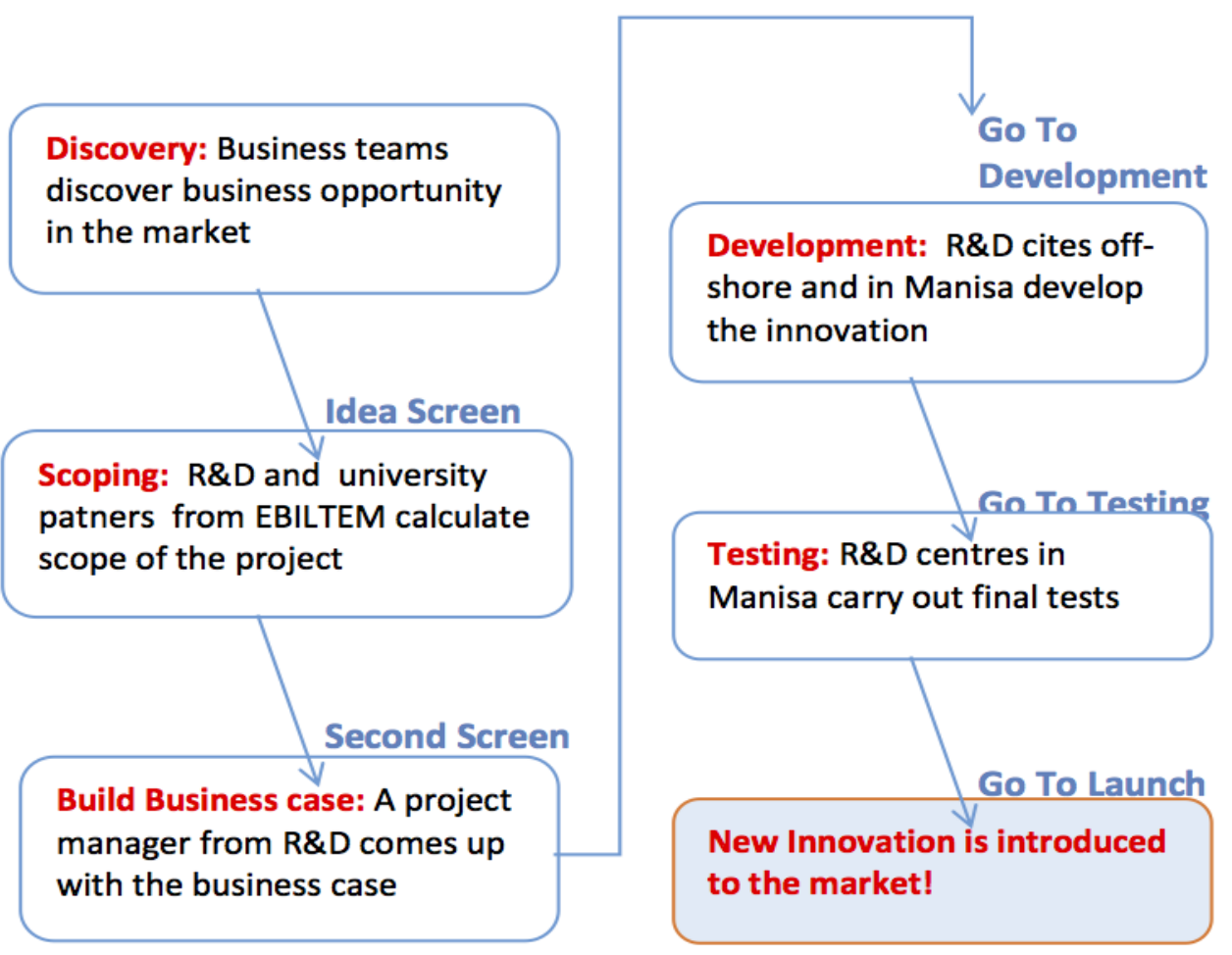


\section{The Vestel 3D Smart TV and its impact}

The Vestel 3D Smart TV was new to the company, the market and the world. The closest competitors to introduce double-screen TV were LG and Samsung, which both released models around the same time as Vestel. The 3D Smart TV is an architectural innovation, because the complete internal system of the TV was changed to accommodate the double-screen feature. Vestel applies both 3D FPR technology and 3D Shutter technology. This was not a mere change of some components of the system, but rather a complete overhaul in how the system interacts.

The 3D Smart TV is still in the growth phase of its product life cycle. Up to now, the innovation was not successful from a business point of view, with disappointing sales and profit figures. The innovation promises potential to make a big impact in the market, but has failed to do so until now. The innovation shows many the characteristics of exploration, such as leading-edge technology, high research investments, development of new capabilities, and large risks with uncertain payoffs. For all its performance woes, the 3D Smart TV seems to be aimed at changing Vestel from a manufacturing and efficiency-based company toward a high-tech company that can compete with international A-brands.

\subsection{Discussion of Results}

\section{Cross-case analysis}

In table 1 below we show a brief cross-case analysis, highlighting the differences and similarities between the two companies and their innovation systems.

Table 1: Cross-Case Analysis

\begin{tabular}{|c|c|c|}
\hline & Arçelik & Vestel \\
\hline Executive representation & $\begin{array}{l}\text { A technology executive and an } \\
\text { innovation director }\end{array}$ & None or informal \\
\hline Coordination & $\begin{array}{l}\text { Central is facilitating and } \\
\text { managing processes }\end{array}$ & Stable process \\
\hline Configurations & $\begin{array}{l}\text { Ideas and development from } \\
\text { inside and outside }\end{array}$ & $\begin{array}{l}\text { Ideas from outside, } \\
\text { development inside }\end{array}$ \\
\hline Archetype & $\begin{array}{l}\text { Combination of Interactive } \\
\text { model and Open innovation }\end{array}$ & $\begin{array}{l}\text { Combination of Technology- } \\
\text { push model and open } \\
\text { innovation }\end{array}$ \\
\hline Exploration-exploitation & Mostly exploitation & Mostly exploration \\
\hline Business success & Big success & Uncertain \\
\hline Fit with innovation system & $\begin{array}{l}\text { Innovation fits the system, does } \\
\text { not change it }\end{array}$ & $\begin{array}{l}\text { Innovation geared at changing } \\
\text { the system }\end{array}$ \\
\hline
\end{tabular}

In the case of Arçelik we see a system that is directly tied to the executive level, with many actors that can be combined into different configurations. The central R\&D function is facilitating and managing those configurations. Configurations can be adapted depending on where new ideas come from. The dominant configuration is the interactive model combined with the open model, taking technology and market developments and internal and external developments into account. The successful innovation of the Telve fits the system and exploits its capabilities. Arçelik's innovation system has evolved gradually during the last 30 years, without too many leaps and bounds.

In the case of Vestel we see a system with a more stable configuration. Consequently, it does not need continuous (centralized) coordination. The dominant configuration for the 3D Smart TV and similar innovations is the technology push model combined with the open model, using ideas developed by external parties or by satellite R\&D centers and then developing those ideas internally. As indicated, the traditional core business of Vestel seems to follow a different configuration, that, unfortunately we cannot analyze with the current data. The technologically advanced 3D Smart TV innovation has met with uncertain business success, but explores new technology and points toward potential changes in Vestel's innovation system.

\section{Implications}

Carlsson et al. (2002) indicate that innovation systems consist of components, the relationships among them, and their characteristics or attributes. We find that using a company innovation system approach, first, we can map 
the main components of companies' innovation systems, such as executive level representation, central innovation departments, de-central departments in regions or attached to the business units and business teams. Second, we can indicate the relationships between those components, e.g., as a reconfigurable system facilitated by a central coordinator (cf., Arçelik), or as a more fixed process, where different actors are involved in different stages (cf., Vestel). Third, we can identify the company innovation systems' characteristics, such as exploration-exploitation, the dynamics of the system and the fit between the innovation outputs and the system capabilities.

Coriat \& Weinstein (2002) and Chen et al. (2015) indicate that external and internal innovation systems are intertwined, hence we should be careful to include the effects of external innovation systems on the company innovation system. Our case examples confirm and highlight this issue. Focusing on the internal innovation systems only would result in a distorted image. This again brings up the question of the system border definition. For analyzing company innovation systems, it seems unlikely that we can rely on the legal boundary of the company only. Alternative boundary definitions and criteria may need to be explored.

Another aspect that we may gather from the case examples is emphasis on interaction, learning and 'new combinations' (cf., Edquist, 1997). We can detect where new combinations come from and how the innovation system can be configured and re-configured to respond to such new combinations, or to create them. In the innovation process approach, such observation are usually considered as 'external', new combinations are assumed to 'just emerge', or their emergence is separately studied as the 'fuzzy front end' of innovation. In the innovation systems approach, the mechanism of how new combinations happen is built into the analysis: they come from interaction between the actors and resources in the system. Admittedly, a lot of conceptual and empirical work needs to be done to clearly demonstrate this principle.

Next, combining the concept of company innovation system with the cases, we can integrate innovation system and innovation process. An innovation process becomes one of many possible configurations within the innovation system. According to Ortt and Van der Duin (2008), a company may choose a different configuration of its innovation process, contingent upon the type of innovation, the type of business, the resources available, or the external environment. Different configurations may exist side by side, as the Vestel example shows us. Some configurations are successful and will be more permanently linked, meaning that the company will use them over and over. Other configurations may be more temporary linked. This also points to the coordination function in a company innovation system. A more permanent configuration, once in place, may require relatively less central coordination, as we may infer from the Vestel example. Temporal configurations and reconfigurations will require continuous coordination, either self-organized and centrally facilitated or centrally managed and controlled, as we may infer from the Arçelik example.

Finally, the company innovation system approach enables us to connect to the concept of explorationexploitation (March, 1991). Existing and permanent configurations exploit the same actors and resources, reinforcing existing capabilities. Such configurations will normally produce successful outputs in the short run, given a stable environment. New and temporal configurations explore new combinations of actors and resources, thereby developing new capabilities. Such configurations require investments with uncertain benefits. Some of them will be huge business successes, others may be outright business failures, but may still contribute to developing new capabilities that enable the innovation system to evolve. The paradoxical finding from our case examples is that the company with a more stable configuration (Vestel) seems to have developed a more exploratory innovation, whereas the company with more flexible and temporary configurations (Arçelik) has developed an innovation that exploits existing capabilities. This may be an issue in the integrity of our data, or a more conceptual issue that should be addressed in further research.

\section{CONCLUSION}

We conclude with relating our findings back to the objectives of the paper, deriving preliminary academic and practical implications, and addressing limitations and scope for further research.

\subsection{Objective and Findings}

The objective of this paper was to conceptualize the company as an innovation system and to explore this concept using two case examples. We propose the company innovation system approach as a relevant addition to and a generalization of the innovation process approach.

We conclude that the company innovation system approach builds on existing theoretical foundations. It is also firmly related to the rich theory and data of innovation systems research on other levels of analysis, national, 
sectoral, regional and technological. It allows us to identify companies' innovation systems and the differences between them. It provides additional and complementary insights to the innovation process approach.

We find that using the company innovation system approach, we can map the components of innovation systems at the company level, we can indicate the relationships between those components and we can identify system characteristics such as relationships with external innovation systems, open versus closed, archetypical configurations, the emergence of new combinations, coordination mechanisms and exploration versus exploitation.

\subsection{Academic and Practical Implications}

This research has academic and practical implications. Academically, we propose that innovation management issues can be analyzed using the company innovation system approach. We also propose that for certain issues and characteristics, such as cross-functional cooperation, learning and knowledge, the emergence of new combinations, and coordination of the innovation functions, can be better analyzed and deeper understood using a company innovation system approach instead of an innovation process approach.

Practically, companies need to address and often struggle with issues of innovation system design (who or which part of the system is responsible for what), innovation system structure (how do the different parts of the system work together) and innovation system coordination (how to ensure that the system is productive, fulfills its objectives, and is stable). A well-conceptualized and validated company innovation system approach may provide managers with the relevant insights to address those issues. Which brings us to future research.

\subsection{Scope for Future Research}

The implications stated above are, at this moment, highly tentative and preliminary. The current paper provides merely an initial conceptualization of the company as an innovation system. Further conceptual work is needed to flesh out the concept and its sub-concepts, to ensure the ability to test and falsify these concepts, and to clarify the connections with related concepts. All the analytical and methodological aspects of innovation systems as identified by Carlsson et al. (2002) should be addressed and clarified. Specific issues that come to mind are: the system definition/boundary, e.g., a strictly legal definition of the company versus a stakeholder involvement definition; the role of the system design principles (e.g., Van de Ven, 1986; Morgan 1986); the possible configurations of the system, archetypical, permanent or temporary (e.g., Teece, 1996; Chen et al., 2015); the governance and institutional characteristics of the system (e.g., Van de Ven, 1986; Teece, 1996); a definition of the elementary units of the system (e.g., Granstrand, 1998; Lakhal et al, 1999); the roles of resources (Granstrand, 1998) and capabilities (Coriat \& Weinstein, 2002); the dynamic and evolutionary aspects of the concept (Carlsson et al., 2002).

Further empirical work is needed to do the actual testing and to demonstrate the usefulness of the approach for analyzing innovation in companies. Such empirical work could start with mapping the innovation system of companies using the case method, making cross-sectional comparisons between companies, or following the evolution of specific company innovation systems over time. Specifically, as Carlsson et al. (2002) indicate that, due to the continuous feedback in the system produced by its interactions, we should be careful with 'snapshots'. Therefore, longitudinal research is strongly preferred.

Upon availability of a sufficient basis of empirical observations, further questions could be empirically tackled, such as the contingency between system structure/governance and the environment or the relationship between system structure/governance and innovative performance.

We thank Dr. Marc Zegveld (IBM) for his initial ideas and work on the concept of company innovation system at the Delft University of Technology. 


\section{REFERENCES}

Anwar, A.A. (2017). Vestel 3D Smart TV final module. Assignment for MGMT401 Technology and Innovation Management. Özyegin University Business School.

Arçelik A.Ş. Annual Reports 2004, 2014 and 2016.

Arçelik A.Ş Website. www.arcelikas.com (accessed 21 April 2017).

Ashby, W.R. (1962). Principles of the self-organizing system, in: Principles of Self-Organization: Transactions of the University of Illinois Symposium, H. Von Foerster and G. W. Zopf, Jr. (eds.), Pergamon Press: London, UK, 255-278.

Başarır, S. (2005). A Comparative Study on Design of Turkish Coffee Brewing Machines for Self-Service: "Telve", "Kahwe" and "Gondol". A Thesis Submitted to the Graduate School of Engineering and Sciences of İzmir Institute of Technology in Partial Fulfillment of the Requirements for the Degree of MASTER OF SCIENCE in Industrial Design.

Carlsson, B., Jacobsson, S., Holmén, M., \& Rickne, A. (2002). Innovation Systems: Analytical and Methodological Issues. Research Policy, 31(2), 233-245.

Carlsson, B. \& Stankiewicz, R. (1991). On the nature, function and composition of technological systems. Journal of Evolutionary Economics, 1(2), 93-118.

Chen, J., Huang, S-f., \& Xu, Q-r. (2015). Firm Innovation Systems: Perspectives of Researches on State-owned Key Enterprises. Frontiers of Engineering Management, 2(1), 64-70.

Chesbrough, H. (2003). The logic of open innovation: managing intellectual property. California Management Review, 45(3), 33-58.

Cooke, Ph., Uranga, M.G., \& Etxebarria, G. (1997). Regional innovation systems: Institutional and organisational dimensions. Research Policy, 26(4-5), 475-491.

Cooper, R.G. (1985). Selecting winning new product projects: Using the NewProd system. Journal of Product Innovation Management 2(1), 34-44.

Cooper, R.G. (1990). Stage-gate systems: a new tool for managing new products. Business Horizons, 33(3), 44-54.

Cooper, R.G. (2008). Perspective: The Stage-Gate ${ }^{\circledR}$ idea-to-launch process-Update, what's new, and NexGen systems. Journal of Product Innovation Management, 25(3),213-232.

Coriat, B. \& Weinstein, O. (2002). Organizations, firms and institutions in the generation of innovation. Research Policy, 31(2), 273-290.

Edquist, Ch. (1997). Systems of innovation: technologies, institutions, and organizations. Routledge, London.

Gawer, A. \& Cusumano, M.A. (2014). Industry platforms and ecosystem innovation. Journal of Product Innovation Management, 31(3), 417-433.

Granstrand, O. (1998). Towards a theory of the technology-based firm." Research policy 27.5 (1998): 465-489.

Granstrand, O. (2000). Corporate Innovation Systems: A Comparative Study of Multi-Technology Corporations in Japan, Sweden and the USA. Paper submitted to the Dynacom project.

Iansiti, M. \& Levien, R. (2004). Strategy as ecology. Harvard Business Review, 82(3), 68-81.

Lakhal, S., Martel, A., Oral, M., \& Montreuil, B. (1999). Network companies and competitiveness: A framework for analysis. European Journal of Operational Research, 118(2), 278-294.

Lundvall, B-A. (1992). National systems of innovation: An analytical framework. Pinter, London.

Malerba, F. (2002). Sectoral systems of innovation and production. Research Policy 31(2), 247-264.

Moore, J.F. (1993). Predators and prey: a new ecology of competition. Harvard Business Review, 71(3), 75-83.

Morgan, G. (1986). Images of organization. Sage Publications, Beverly Hills.

Ortt, J.R. \& Van der Duin, P.A. (2008). The evolution of innovation management towards contextual innovation. European Journal of Innovation Management, 11(4), 522-538.

Rothwell, R. (1994). Towards the fifth-generation innovation process. International Marketing Review, 11(1), 7-31.

Senturk, R. (2011). An Open Innovation Story From Turkey: VESTEL Magneto. www.innovationmanagement.se (accessed 8 Nov. 2016). 
Teece, D.J (1996). Firm organization, industrial structure, and technological innovation. Journal of Economic Behavior \& Organization, 31(2), 193-224.

Tidd, J. \& Bessant, J. (2013) Managing Innovation: Integrating Technological, Market and Organizational Change - 5th Edition. Wiley, Hoboken.

Trott, P. (2011). Innovation management and new product development - 5th Edition. Pearson education, Harlow, UK.

Turkish Coffee World. www.turkishcoffeeworld.com/Arcelik-BekoTelve-Turkish-Coffee-Machine-p/tcw-b002.htm (accessed 21 April 2017).

Uzun, P. (2017) Arçelik Telve - Final. Assignment for MGMT401 Technology and Innovation Management. Özyegin University Business School.

Van de Ven, A.H. (1986) Central problems in the management of innovation. Management Science, 32(5), 590-607.

Vestel Annual Report 2015.

Vestel Ventures. www.vestelventures.com (accessed 8 Nov. 2016). 